\title{
Application of Artificial Intelligence in the Detection and Characterization of Colorectal Neoplasm
}

\author{
Kyeong Ok Kim${ }^{1}$ and Eun Young Kim² \\ ${ }^{1}$ Division of Gastroenterology and Hepatology, Department of Internal Medicine, Yeungnam University College of Medicine, and \\ ${ }^{2}$ Division of Gastroenterology and Hepatology, Department of Internal Medicine, Daegu Catholic University School of Medicine, \\ Daegu, Korea
}

\author{
Article Info \\ Received June 12, 2020 \\ Accepted June 28, 2020 \\ Published online August 12, 2020 \\ Corresponding Author \\ Eun Young Kim \\ ORCID https://orcid.org/0000-0003-3965-9964 \\ E-mail kimey@cu.ac.kr
}

\begin{abstract}
Endoscpists always have tried to pursue a perfect colonoscopy, and application of artificial intelligence (Al) using deep-learning algorithms is one of the promising supportive options for detection and characterization of colorectal polyps during colonoscopy. Many retrospective studies conducted with real-time application of Al using convolutional neural networks have shown improved colorectal polyp detection. Moreover, a recent randomized clinical trial reported additional polyp detection with shorter analysis time. Studies conducted regarding polyp characterization provided additional promising results. Application of Al with narrow band imaging in real-time prediction of the pathology of diminutive polyps resulted in high diagnostic accuracy. In addition, application of AI with endocytoscopy or confocal laser endomicroscopy was investigated for realtime cellular diagnosis, and the diagnostic accuracy of some studies was comparable to that of pathologists. With Al technology, we can expect a higher polyp detection rate with reduced time and cost by avoiding unnecessary procedures, resulting in enhanced colonoscopy efficiency. However, for Al application in actual daily clinical practice, more prospective studies with minimized selection bias, consensus on standardized utilization, and regulatory approval are needed. (Gut Liver 2021;15:346-353)
\end{abstract}

Key Words: Polyp; Colon; Colonoscopy; Artificial intelligence; Convolutional neural network

\section{INTRODUCTION}

The incidence of colorectal cancer (CRC), the third most common cancer worldwide, ${ }^{1}$ has been steadily increasing in the Republic of Korea recently. Because most of the CRC arise from adenomas, detection and complete removal of these precancerous lesions can reduce the incidence and mortality associated with CRC., ${ }^{2,3}$ However, for the effective prevention of CRC, high-quality colonoscopy that detects all the polyps, is a prerequisite. Adenoma detection rate (ADR) has been considered as one of the important quality indicators of colonoscopy, and the inverse association between ADR and incidence of interval CRC has been established. ${ }^{4,5}$ Because colonoscopy may not be perfect, many efforts to enhance ADR have been made. ${ }^{6}$
Artificial intelligence (AI), one of the promising technologies, can mitigate the shortcomings of colonoscopy. As it is easy to obtain polyp images to provide enough data for AI training, many studies using this technology have been reported lately. ${ }^{7}$ Well-trained AI modelling can increase polyp identification and optical diagnosis. Especially, its use can increase the detection rate of polyps in the right colon, where a higher miss rate is understandably anticipated with conventional colonoscopy. ${ }^{8}$

In this review, we aim to contemplate the current status and future directions of AI applications, including technologies, applications, efficacy, and unmet needs, regarding colorectal neoplasm. 
COMPUTER-AIDED DIAGNOSIS AND DEEP-LEARNING FOR DETECTION AND CHARACTERIZATION OF THE COLORECTAL POLYPS

AI, having machine intelligence that is different from the natural intelligence displayed by humans and other animals, ${ }^{9}$ can learn and solve problems. ${ }^{10}$ Earlier, machine learning (ML) had been the main focus of AI. A computervision algorithm, developed by computer scientists based on earlier ML research for the detection of colorectal polyps was "hand-crafted," based on the features adopted by the designers. ${ }^{11}$ In other words, human efforts or instructions were needed for extracting features, such as color, shape, or texture of polyps, because the earlier ML could learn only the classification of the extracted images. ${ }^{12} \mathrm{Al}-$ though the "hand-crafted" algorithm showed high accuracy, the risk of missing the lesions without those extracted features or obtaining false positive results was of concern because it was designed to detect the lesions with certain features chosen by designers. In addition, actual clinical application was limited due to the difference in image quality and also slow processing time. ${ }^{11}$

Deep-learning (DL) algorithm, one of the subtype of ML introduced in the 1980s, could overcome the limitation of earlier ML by combining both the extraction and classification of image features using deep neural networks (DNN). ${ }^{13}$ The innovative method of DNN gained significant attention because of self-learning capability of DL that could automatically identify polyp and non-polyp features from the huge dataset, instead of capturing specific features of a polyp using several networks. Self-extraction, the key feature, was achieved using backpropagation algorithm and changing the internal parameters of each neural network layer. ${ }^{14}$

Among the variable classes of DNN for image and video applications, convolutional neural network (CNN), the most popular method, can carry out layers of convolutions and can completely connect layers to unite all features in the final outcome. ${ }^{15,16}$ Provided with sufficient annotated data, CNNs can be trained to describe, in detail, what they see and discriminate polyps from non-polypoid lesions. ${ }^{11}$ Currently, AI can be trained with enough input data, thanks to the easy accessibility of big data, aiding rapid progress in the research and application of $\mathrm{AI}$ in colonoscopic polyp detection and characterization. ${ }^{17}$

\section{STUDIES RELATED TO APPLICATION OF AI} IN COLONOSCOPY

\section{Al for detection of colorectal polyp}

Since the initial study regarding computer-aided detection based on "hand-crafted" data, ${ }^{18}$ the performance of AI has improved, especially with the introduction of DL, for colorectal neoplasm detection. ${ }^{19,20}$ Table 1 shows the summary of the clinical studies of AI for the detection of colorectal polyps. ${ }^{18-26}$

Urban et al. ${ }^{20}$ reported the first real-time application. They initially pretrained AI using ImageNet and then trained the deep CNNs. The algorithm was tested with multiple sets of colonoscopic images and 11 challenging videos sets. The result was very promising with $97 \%$ sensitivity, $95 \%$ specificity, and $96 \%$ overall accuracy. For the practical utilization in real-world, the $\mathrm{CNN}$-assisted video was reviewed by experts. During the index colonoscopy, 28 polyps were noted in nine standard colonoscopic videos. Experts could identify 36 polyps without and 45 polyps with $\mathrm{CNN}$ assistance. The additional 17 polyps identified with $\mathrm{CNN}$ assistance were not larger than $10 \mathrm{~mm}$ in size. Further, the algorithm was faster than the real-time analysis by endoscopists $(10 \mathrm{~ms} /$ frame vs $33-40 \mathrm{~ms} /$ frame). Meanwhile, Yu et al. ${ }^{24}$ developed a novel three-dimensional CNN algorithm that could learn more representative spatiotemporal features and improve performance of automated polyp detection.

Wang et al. ${ }^{21}$ developed a CNN system that processed data in real-time with a 77 millisecond delay on monitor, in which, a blue box appeared around the area of the polyp upon its detection, along with an alarm. They randomized the colonoscopy of about 1,058 patients into those using this system and the standard one and proved an increased ADR in AI ( $29.1 \%$ vs $20.3 \%$, respectively) with minimal delay in examining time. However, the robust detection rate was limited to polyps smaller than $10 \mathrm{~mm}$ in size, and $43.6 \%$ of the polyps were hyperplastic polyps with low malignant potential. ${ }^{27,28}$ The most recent meta-analysis of three randomized controlled trial of $\mathrm{AI}$-assisted colonoscopy reported $32.9 \%$ of ADR $(20.8 \%$ in standard colonoscopy, risk ratio $[R R]=1.58, \mathrm{p}<0.001)$ and $43.0 \%$ of polyp detection rate $(27.8 \%$ in standard colonoscopy, $\mathrm{RR}=1.55$, $\mathrm{p}<0.001) .{ }^{29}$ AI utility in screening colonoscopy to improve ADR looks optimistic.

\section{Al for characterization of colorectal neoplasm}

Accurate histologic diagnosis of the colorectal polyp before resection is desired because endoscopic resection and pathologic evaluation of lesions with very low risk of malignant potential may result in waste of time and cost. On 
Table 1. Clinical Studies of Artificial Intelligence for the Detection of Colorectal Polyps

\begin{tabular}{|c|c|c|c|c|c|}
\hline Author (year) & Study design & Algorithm type & Dataset & Processing time & Results \\
\hline $\begin{array}{l}\text { Wang et al. } \\
(2019)^{21}\end{array}$ & $\begin{array}{l}\text { Randomized } \\
\text { controlled study }\end{array}$ & $\begin{array}{l}\text { Convolutional } \\
\text { neural network }\end{array}$ & 5,545 Images & $\begin{array}{l}25 \mathrm{fps} \text { with } 77 \mathrm{~ms} \\
\text { latency }\end{array}$ & $9 \%$ Increase of ADR \\
\hline $\begin{array}{l}\text { Klare et al. } \\
(2019)^{22}\end{array}$ & $\begin{array}{l}\text { Prospective } \\
\text { In vivo }\end{array}$ & $\begin{array}{l}\text { Convolutional } \\
\text { neural network }\end{array}$ & 55 Live colonoscopies & 50 ms latency & $\begin{array}{l}\text { Sensitivity } 75 \% \text { /polyp } \\
\text { ADR } 29 \% \text { (31\% in endoscopist) }\end{array}$ \\
\hline $\begin{array}{l}\text { Urban et al. } \\
(2018)^{20}\end{array}$ & $\begin{array}{l}\text { Retrospective } \\
\text { Ex vivo }\end{array}$ & $\begin{array}{l}\text { Convolutional } \\
\text { neural network }\end{array}$ & $\begin{array}{l}\text { Image dataset: } 8,641 \\
\text { polyps } \\
\text { Video: } 20 \text { colonoscopies }\end{array}$ & $\begin{array}{c}10 \text { ms/frame } \\
\text { (real-time) }\end{array}$ & $\begin{array}{l}\text { Image dataset: accuracy } 96.4 \% \\
\text { AUROC } 0.991\end{array}$ \\
\hline $\begin{array}{l}\text { Misawa et al. } \\
(2018)^{19}\end{array}$ & $\begin{array}{l}\text { Retrospective } \\
\text { Ex vivo }\end{array}$ & $\begin{array}{l}\text { Convolutional } \\
\text { neural network }\end{array}$ & 135 Video clips & No description & $\begin{array}{l}\text { Sensitivity } 90 \% \\
\text { Specificity } 63.3 \% \\
\text { Accuracy } 76.5 \%\end{array}$ \\
\hline $\begin{array}{l}\text { Zhang et al. } \\
\qquad(2017)^{23}\end{array}$ & $\begin{array}{l}\text { Retrospective } \\
\text { Ex vivo }\end{array}$ & $\begin{array}{l}\text { Convolutional } \\
\text { neural network }\end{array}$ & $\begin{array}{l}150 \text { Random+30 NBI } \\
\text { images }\end{array}$ & No description & $\begin{array}{l}\text { Sensitivity } 98 \% \\
\text { PPV } 99 \% \\
\text { AUROC } 1.00\end{array}$ \\
\hline $\begin{array}{l}\text { Yu et al. } \\
(2017)^{24}\end{array}$ & $\begin{array}{l}\text { Retrospective } \\
\text { Ex vivo }\end{array}$ & $\begin{array}{l}\text { Convolutional } \\
\text { neural network }\end{array}$ & ASU-Mayo 20 videos & $1.23 \mathrm{~s} /$ frame & $\begin{array}{l}\text { Sensitivity } 7 \% \\
\text { PPV } 88 \%\end{array}$ \\
\hline $\begin{array}{l}\text { Angermann et } \\
\text { al. }(2017)^{25}\end{array}$ & $\begin{array}{l}\text { Retrospective } \\
\text { Ex vivo }\end{array}$ & Hand-crafted & No description & $\begin{array}{l}20-185 \mathrm{~ms} \\
0.3-1.8 \text { s delay }\end{array}$ & $\begin{array}{l}\text { Sensitivity 100\%/polyp } \\
\text { PPV50\% }\end{array}$ \\
\hline $\begin{array}{l}\text { Tajbakhsh et al. } \\
(2015)^{26}\end{array}$ & $\begin{array}{l}\text { Retrospective } \\
\text { Ex vivo }\end{array}$ & Hand-crafted & No description & $2.6 \mathrm{~s} /$ frame & $\begin{array}{l}\text { Sensitivity } 48 \% \text { on proprietary } \\
\text { database } \\
\text { Sensitivity } 88 \% \text { in CVC-colon DB }\end{array}$ \\
\hline $\begin{array}{l}\text { Karkanis et al. } \\
(2003)^{18}\end{array}$ & $\begin{array}{l}\text { Retrospective } \\
\text { Ex vivo }\end{array}$ & Hand-crafted & 180 Still images & $1.5 \mathrm{~m} / \mathrm{video}$ & $\begin{array}{l}\text { Sensitivity } 94 \% \\
\text { Specificity } 99 \%\end{array}$ \\
\hline
\end{tabular}

$\mathrm{ADR}$, adenoma detection rate; $\mathrm{AUROC}$, area under the receiver operating characteristics; NBI, narrow band imaging; PPV, positive predictive value; ASU, Arizona State University; CVC, computer vision center; DB, data base.

the other hand, incomplete resection of lesions with high risk of malignancy should be avoided. Therefore, various advanced endoscopic techniques with image enhancement for optical diagnosis have been introduced, and various studies concerning the application of AI to these endoscopic systems have also been steadily reported to date (Table 2).

Narrow band imaging (NBI; Olympus Corp., Tokyo, Japan), an image-enhanced endoscopy used for the observation of microstructure or capillaries of colorectal neoplasm, could discriminate each polyp well, based on the pit and vascular pattern. ${ }^{30}$ Tischendorf et al..$^{31}$ and Gross et al. ${ }^{32}$ investigated AI application to NBI (excluding its performance enhancement) for the characterization of colon polyps. They both extracted nine vessel features from the NBI images in a similar manner and sorted them into neoplastic and non-neoplastic lesions using a support vector machine (SVM), a discriminated ML model..$^{15}$ The diagnostic accuracies of the two studies were $85.3 \%$ and $93.1 \%$, respectively. In addition, Gross et al. ${ }^{32}$ proved superior accuracy of AI-assisted diagnosis compared to that of nonexperts in differentiating colorectal polyps smaller than 10 $\mathrm{mm}$ in size, suggesting that AI could be a good support for the beginners of endoscopy.

Another Japanese group developed a real-time image recognition system that could achieve $93.2 \%$ accuracy in real-time prediction of diminutive polyp pathology. ${ }^{33}$ In addition, the follow-up recommendation based on the prediction by that model showed $92.7 \%$ consistency with Preservation and Incorporation of Valuable Endoscopic Innovations (PIVI)-2 criteria of American Society for Gastrointestinal Endoscopy for "resect-and-discard" strategy. ${ }^{34}$ Resect and discard strategy can bring a substantial economic benefit.

Two groups carried out retrospective studies based on DL. Byrne et al. ${ }^{35}$ developed CNN model using NBI video frames. Although the model could not make adequate credence of histology prediction in $15 \%$ of polyps, it could differentiate diminutive adenomas from hyperplastic polyps with $94 \%$ accuracy. The sensitivity and specificity for detecting adenoma were $98 \%$ and $83 \%$, respectively. Chen et al..$^{36}$ also developed a similar model, a DNN-computer aided diagnosis (CAD), with 2,157 images for identification of about 284 neoplastic or hyperplastic polyps smaller than $5 \mathrm{~mm}$ in size, with $89.6 \%$ positive predictive value (PPV) and 91.5\% negative predictive value (NPV). Consequently, among 117 tubular adenomas, DNN-CAD could diagnose high grade dysplasia with $100 \%$ sensitivity and $94 \%$ specificity. The performance of DNN-CAD, when compared to that of four endoscopists with less than 1 year of experience, was superior with a shorter procedure time and perfect intra-observer agreement (kappa score of 1). The result of the above-mentioned two studies could satisfy the PIVI-2 threshold (90\% NPV for adenoma detection) 
Table 2. Clinical Studies of Artificial Intelligence for Characterization of Colorectal Polyps

\begin{tabular}{|c|c|c|c|c|c|c|}
\hline Author (year) & Study design & $\begin{array}{c}\text { Classification target } \\
\text { and base }\end{array}$ & Algorithm type & Image modality & Dataset & Results \\
\hline $\begin{array}{l}\text { Byrne et al. } \\
\qquad(2019)^{35}\end{array}$ & Retrospective & $\begin{array}{l}\text { Histology of } \\
\text { diminutive polyp }\end{array}$ & $\begin{array}{l}\text { Convolutional } \\
\text { neural network }\end{array}$ & NBI video frames & $\begin{array}{l}125 \text { Diminutive } \\
\text { polyp videos }\end{array}$ & $\begin{array}{l}\text { Sensitivity } 98 \% \\
\text { Specificity } 83 \% \\
\text { Accuracy } 94 \%\end{array}$ \\
\hline $\begin{array}{l}\text { Chen et al. } \\
(2018)^{36}\end{array}$ & Retrospective & $\begin{array}{l}\text { Neoplastic or hy- } \\
\text { perplastic polyp } \\
<5 \mathrm{~mm}\end{array}$ & $\begin{array}{l}\text { Convolutional } \\
\text { neural network }\end{array}$ & Magnifying NBI & $\begin{array}{r}284 \text { Diminutive } \\
\text { polyps image }\end{array}$ & $\begin{array}{l}\text { Sensitivity } 96.3 \% \\
\text { Specificity } 78.1 \% \\
\text { Accuracy } 90.1 \%\end{array}$ \\
\hline $\begin{array}{l}\text { Mori et al. } \\
\qquad(2018)^{44}\end{array}$ & Prospective & $\begin{array}{l}\text { Diagnosis of neo- } \\
\text { plastic diminu- } \\
\text { tive polyp }\end{array}$ & SVM & $\begin{array}{l}\text { Endocytoscopy with NBI } \\
\text { and stained images }\end{array}$ & $\begin{array}{l}466 \text { Diminutive } \\
\text { polyps from } \\
325 \text { patients }\end{array}$ & Prediction rate $98.1 \%$ \\
\hline $\begin{array}{l}\text { Takeda et al. } \\
(2017)^{43}\end{array}$ & Retrospective & Invasive CRC & SVM & $\begin{array}{l}\text { Endocytoscopy with NBI } \\
\text { and stained images }\end{array}$ & 200 Images & $\begin{array}{l}\text { Sensitivity } 89.4 \% \\
\text { Specificity } 98.9 \% \\
\text { Accuracy } 94.1 \%\end{array}$ \\
\hline $\begin{array}{l}\text { Kominami et al. } \\
(2016)^{33}\end{array}$ & Prospective & Histology & $\begin{array}{l}\text { SVM with logistic } \\
\text { regression }\end{array}$ & Magnifying NBI & $\begin{array}{l}118 \text { Colorectal } \\
\text { lesions }\end{array}$ & $\begin{array}{l}\text { Sensitivity } 95.9 \% \\
\text { Specificity } 93.3 \% \\
\text { Accuracy } 94.9 \%\end{array}$ \\
\hline $\begin{array}{l}\text { Misawa et al. } \\
(2016)^{46}\end{array}$ & Retrospective & $\begin{array}{l}\text { Microvascular } \\
\text { findings }\end{array}$ & SVM & Endocytoscopy with NBI & 100 Images & $\begin{array}{l}\text { Sensitivity } 84.5 \% \\
\text { Specificity } 97.6 \% \\
\text { Accuracy } 90.0 \%\end{array}$ \\
\hline $\begin{array}{l}\text { Mori et al. } \\
(2015)^{42}\end{array}$ & Retrospective & $\begin{array}{l}\text { Neoplastic } \\
\text { changes in } \\
\text { small polyps }\end{array}$ & $\begin{array}{l}\text { Multivariate } \\
\text { regression } \\
\text { analysis }\end{array}$ & Endocytoscopy & $\begin{array}{l}176 \text { Polyps from } \\
152 \text { patients }\end{array}$ & $\begin{array}{l}\text { Sensitivity } 92 \% \\
\text { Specificity } 79.5 \% \\
\text { Accuracy } 89.2 \%\end{array}$ \\
\hline $\begin{array}{l}\text { Takemura et al. } \\
(2012)^{57}\end{array}$ & Retrospective & Pit pattern & SVM & Magnifying NBI & 371 Images & $\begin{array}{l}\text { Sensitivity } 97.8 \% \\
\text { Specificity } 97.9 \% \\
\text { Accuracy } 97.8 \%\end{array}$ \\
\hline $\begin{array}{l}\text { Gross et al. } \\
(2011)^{32}\end{array}$ & Prospective & $\begin{array}{l}\text { Small colonic } \\
\text { polyp }<10 \mathrm{~mm}\end{array}$ & SVM & Magnifying NBI & $\begin{array}{l}434 \text { Polyps from } \\
214 \text { patients }\end{array}$ & $\begin{array}{l}\text { Sensitivity } 95 \% \\
\text { Specificity } 90.3 \% \\
\text { Accuracy } 93.1 \%\end{array}$ \\
\hline $\begin{array}{l}\text { Tischendorf et } \\
\text { al. }(2010)^{31}\end{array}$ & $\begin{array}{l}\text { Prospective } \\
\text { pilot }\end{array}$ & $\begin{array}{l}\text { Vascularization } \\
\text { features }\end{array}$ & SVM & Magnifying NBI & $\begin{array}{l}209 \text { Polyps from } \\
128 \text { patients }\end{array}$ & $\begin{array}{l}\text { Sensitivity } 90 \% \\
\text { Specificity } 70.2 \% \\
\text { Accuracy } 85.3 \%\end{array}$ \\
\hline $\begin{array}{l}\text { Takemura et al. } \\
(2010)^{39}\end{array}$ & Retrospective & Pit pattern & $\begin{array}{l}\text { HuPAS software } \\
\text { version } 1.3\end{array}$ & $\begin{array}{l}\text { Magnifying NBI with } \\
\text { chromoendoscopy } \\
\text { (crystal violet) }\end{array}$ & 134 Images & Accuracy $98.5 \%$ \\
\hline
\end{tabular}

$\mathrm{NBI}$, narrow band imaging; SVM, support vector machine; CRC, colorectal cancer.

for "leave-in-place" strategy for diminutive hyperplastic polyps. $^{34}$

Although there's a lack of recent further studies, CAD of pit pattern by magnifying chromoendoscopy was done by quantitative analysis of pit structure or texture analysis of endoscopic images. ${ }^{37,38}$ Takemura et al. ${ }^{39}$ reported $98.5 \%$ diagnostic accuracy after automatically evaluating the area, perimeter, major/minor fit ellipse and circularity of the pit using software.

Recently, novel introduction of in vivo contact microscopic imaging modalities, such as endocytoscopy (H290ECI; Olympus Corp.) and confocal laser endomicroscopy (Cellvizio; Mauna Kea Technologies Inc, Paris, France), enabled real-time diagnosis of cellular images. ${ }^{40,41}$ Because both endocytoscopy and endomicroscopy could enhance image analysis with focused fixed-size images, they were ideal to be used in combination with the AI system. They magnified the image with $500-$ or 1,000 - fold power, respectively, during colonoscopy and showed diagnostic accuracy comparable to that of pathologists. The first application of AI in endocytoscopy was assessed by quantitative analysis of six nuclear features, and the accuracy for the detection of neoplastic change was $89.2 \% .{ }^{42}$ Takeda et al. ${ }^{43}$ trained the computer-aided ultrahigh (approximately $\times 400$ ) magnification endoscopy system for the diagnosis of invasive CRC with 5,543 endocytoscopic images. This system, when assessed using 200 endocytoscopic test images, could discriminate invasive cancers with $89.4 \%$ sensitivity, $98.9 \%$ specificity, and $94.1 \%$ accuracy. Mori et al. ${ }^{44}$ assessed the efficacy of an endocytoscopy-based CAD with 466 cases of diminutive polyps, and the NPV for diminutive rectosigmoid adenomas was $93.7 \%$. They also proved that polyp diagnosis with AI, an add-on analysis, could reduce the cost of annual reimbursement for colonoscopy by $18.9 \%$, by leaving 145 rectosigmoid diminutive polyps based on the AI support. ${ }^{45}$ However, AI endocytos- 
copy had a limitation-it needed pre-staining with crystal violet and methylene blue before the extraction of images. Misawa et al. ${ }^{46}$ upgraded the system by combining endocytoscopy with NBI, eliminating the pre-staining step and resulting in $90.0 \%$ overall accuracy and $84.5 \%$ sensitivity within 0.3 seconds.

AI application with confocal endomicroscopy was assessed in several studies, in experimental setting, with promising accuracy. ${ }^{47-50} \mathrm{AI}$ in other advanced endoscopies, including laser-induced fluorescence spectroscopy and autofluorescence endoscopy, was also evaluated retrospectively or prospectively. ${ }^{51-57}$ We can expect that the use of AI in these advanced endoscopies for optical diagnosis could aid the real-time decision making of endoscopists.

\section{Al for combination of detection and characterization of colorectal polyps}

For an endoscopist, both polyp detection and characterization are essential in clinical practice. An ideal scenario would be an AI-assisted immediate detection and characterization of the colorectal polyp. A Japanese group developed novel technologies that included two algorithm systems-one, based on DL algorithm, for the detection of polyps in white light images, and the other, for the prediction of pathology by endocytoscopic images generated by a photograph. ${ }^{58}$ According to the most recent study using CNN, AI system (Single Shot Multibox Detector) could detect 1,246 polyps with $92 \%$ sensitivity, $86 \%$ PPV, and $83 \%$ accuracy in polyp classification. ${ }^{59}$ Although more studies are needed, an ideal colonoscopy for the detection and characterization of colorectal neoplasm seems to be achieved with AI assistance.

\section{Prediction of prognosis}

Prior to DL, SVM was a highly efficient computational tool that classified and regressed best by optimizing a hyperplane with largest functional margin. ${ }^{15}$ Ichimasa et al. ${ }^{60}$ evaluated the predictive factors for lymph node metastasis from endoscopically resected T1 CRC using SVM. Their result showed better sensitivity (100\%), specificity (66\%), and accuracy (69\%) of the AI model than most of the current guidelines. In addition, this model could reduce the unnecessary additional colectomy after endoscopic resection of T1 CRC compared to the current guidelines that lead to misdiagnosis.

\section{UNMET NEEDS AND FUTURE PERSPECTIVES OF AI FOR COLORECTAL NEOPLASM}

Although AI-assisted detection and diagnosis of colorectal neoplasm are promising, most of the studies are retrospective and covered lesions which might have been selected with bias. Well-designed prospective studies that present more reliable data compared to the previous retrospective studies are needed. Most of the studies regarding efficacy of AI deal with polypoid lesions. However, for practical utilization, the efficacy of AI needs to be consistent irrespective of the shape of the polyps. Therefore, more studies with all types of polyps, including polypoid, depressed, or flat type, are needed because these nonpolypoid type lesions are often more aggressive. ${ }^{61}$

In addition, as $\mathrm{AI}$ is trained with high-quality images, the system has to overcome the blurry vision, inadequate preparation status, and variable unpredictable hurdles observed in actual practice. There is a need for real-time application of CAD and randomized controlled comparative study between usage and avoidance of AI.

Previous studies, conducted in a variable design, resulted in different primary outcomes. Because AI development needed both engineers, who dealt with the software, and clinicians, who contributed to the clinical use, the outcomes and study design could be different depending on the study conductors. ${ }^{11}$ Communication and collaboration between these different groups are also needed.

To apply AI in real clinical practice, a regulatory approval of AI-based decision making, the rules of which vary for each country, is an essential step. For that, we need to prove the minimal risk of treatment failure due to the misdiagnosis by $\mathrm{AI}^{22,62}$ So, we need the evaluation of risk stratification for AI system through well-designed randomized clinical trials.

\section{CONCLUSION}

Because colonoscopy cannot completely prevent CRC, AI application in the field of colorectal neoplasm could be one of the promising options for enhancing the efficiency of colonosocpy. Owing to easy accessibility of big data and computer science, the AI technologies for the detection and classification of colorectal polyps have developed rapidly, with studies supporting the advantage of AI use in colonoscopy. However, obstacles, such as insufficient evidence of practical clinical usefulness, lack of consensus on standardized utilization, and need for regulatory approval, exist. For the ideal implementation of AI in actual clinical practice, comprehensive understanding of the strengths and weaknesses of the technology, qualified real-time studies, and accumulation of experience are warranted. 


\section{CONFLICTS OF INTEREST}

E.Y.K. is an editorial board member of the journal but did not involve in the peer reviewer selection, evaluation, or decision process of this article. No other potential conflicts of interest relevant to this article were reported.

\section{ORCID}

Kyeong Ok Kim https://orcid.org/0000-0001-5799-7436

Eun Young Kim https://orcid.org/0000-0003-3965-9964

\section{REFERENCES}

1. American Cancer Society. Cancer Facts \& Figures 2019. Atlanta: American Cancer Society, 2019.

2. Winawer SJ, Zauber AG, Ho MN, et al. Prevention of colorectal cancer by colonoscopic polypectomy. The National Polyp Study Workgroup. N Engl J Med 1993;329:19771981.

3. Nishihara R, Wu K, Lochhead P, et al. Long-term colorectalcancer incidence and mortality after lower endoscopy. N Engl J Med 2013;369:1095-1105.

4. Rex DK, Schoenfeld PS, Cohen J, et al. Quality indicators for colonoscopy. Gastrointest Endosc 2015;81:31-53.

5. Kaminski MF, Regula J, Kraszewska E, et al. Quality indicators for colonoscopy and the risk of interval cancer. N Engl J Med 2010;362:1795-1803.

6. Castaneda D, Popov VB, Verheyen E, Wander P, Gross SA. New technologies improve adenoma detection rate, adenoma miss rate, and polyp detection rate: a systematic review and meta-analysis. Gastrointest Endosc 2018;88:209-222.

7. Liedlgruber M, Uhl A. Computer-aided decision support systems for endoscopy in the gastrointestinal tract: a review. IEEE Rev Biomed Eng 2011;4:73-88.

8. Kudo SE, Mori Y, Misawa M, et al. Artificial intelligence and colonoscopy: current status and future perspectives. Dig Endosc 2019;31:363-371.

9. Wikipedia. Artificial intelligence [Internet]. San Francisco: Wikipedia Foundation, Inc.; c2020 [cited 2020 Mar 30]. Available from: https://en.wikipedia.org/wiki/Artificial_intelligence.

10. Russell S, Norvig P. Artificial intelligence: a modern approach. 3rd ed. Harlow: Pearson Education Limited, 2009.

11. Hoerter N, Gross SA, Liang PS. Artificial intelligence and polyp detection. Curr Treat Options Gastroenterol 2020;18: 120-136.

12. Ahmad OF, Soares AS, Mazomenos E, et al. Artificial intelligence and computer-aided diagnosis in colonoscopy: cur- rent evidence and future directions. Lancet Gastroenterol Hepatol 2019;4:71-80.

13. LeCun Y, Bengio Y, Hinton G. Deep learning. Nature 2015; 521:436-444.

14. Takiyama H, Ozawa T, Ishihara S, et al. Automatic anatomical classification of esophagogastroduodenoscopy images using deep convolutional neural networks. Sci Rep 2018;8: 7497.

15. Yang YJ, Bang CS. Application of artificial intelligence in gastroenterology. World J Gastroenterol 2019;25:1666-1683.

16. Yoon HJ, Kim JH. Lesion-based convolutional neural network in diagnosis of early gastric cancer. Clin Endosc 2020; 53:127-131.

17. Choi J, Shin K, Jung J, et al. Convolutional neural network technology in endoscopic imaging: artificial intelligence for endoscopy. Clin Endosc 2020;53:117-126.

18. Karkanis SA, Iakovidis DK, Maroulis DE, Karras DA, Tzivras M. Computer-aided tumor detection in endoscopic video using color wavelet features. IEEE Trans Inf Technol Biomed 2003;7:141-152.

19. Misawa M, Kudo SE, Mori Y, et al. Artificial intelligenceassisted polyp detection for colonoscopy: initial experience. Gastroenterology 2018;154:2027-2029.

20. Urban G, Tripathi P, Alkayali T, et al. Deep learning localizes and identifies polyps in real time with $96 \%$ accuracy in screening colonoscopy. Gastroenterology 2018;155:10691078.

21. Wang P, Berzin TM, Glissen Brown JR, et al. Real-time automatic detection system increases colonoscopic polyp and adenoma detection rates: a prospective randomised controlled study. Gut 2019;68:1813-1819.

22. Klare P, Sander C, Prinzen M, et al. Automated polyp detection in the colorectum: a prospective study (with videos). Gastrointest Endosc 2019;89:576-582.

23. Zhang R, Zheng Y, Mak TW, et al. Automatic detection and classification of colorectal polyps by transferring low-level $\mathrm{CNN}$ features from nonmedical domain. IEEE J Biomed Health Inform 2017;21:41-47.

24. Yu L, Chen H, Dou Q, Qin J, Heng PA. Integrating online and offline three-dimensional deep learning for automated polyp detection in colonoscopy videos. IEEE J Biomed Health Inform 2017;21:65-75.

25. Angermann Q, Bernal J, Sánchez-Montes C, et al. Towards real-time polyp detection in colonoscopy videos: adapting still frame-based methodologies for video sequences analysis. In: Cardoso MJ, Arbel T, Luo X, eds. Computer assisted and robotic endoscopy and clinical image-based procedures. Cham: Springer, 2017:29-41.

26. Tajbakhsh N, Gurudu SR, Liang J. Automated polyp detection in colonoscopy videos using shape and context information. IEEE Trans Med Imaging 2016;35:630-644. 
27. Noshirwani KC, van Stolk RU, Rybicki LA, Beck GJ. Adenoma size and number are predictive of adenoma recurrence: implications for surveillance colonoscopy. Gastrointest Endosc 2000;51(4 Pt 1):433-437.

28. Martínez ME, Baron JA, Lieberman DA, et al. A pooled analysis of advanced colorectal neoplasia diagnoses after colonoscopic polypectomy. Gastroenterology 2009;136:832841.

29. Aziz M, Fatima R, Dong C, Lee-Smith W, Nawras A. The impact of deep convolutional neural network-based artificial intelligence on colonoscopy outcomes: a systematic review with meta-analysis. J Gastroenterol Hepatol 2020;35:16761683.

30. Tanaka S, Sano Y. Aim to unify the narrow band imaging (NBI) magnifying classification for colorectal tumors: current status in Japan from a summary of the consensus symposium in the 79th Annual Meeting of the Japan Gastroenterological Endoscopy Society. Dig Endosc 2011;23 Suppl 1: 131-139.

31. Tischendorf JJ, Gross S, Winograd R, et al. Computer-aided classification of colorectal polyps based on vascular patterns: a pilot study. Endoscopy 2010;42:203-207.

32. Gross S, Trautwein C, Behrens A, et al. Computer-based classification of small colorectal polyps by using narrowband imaging with optical magnification. Gastrointest Endosc 2011;74:1354-1359.

33. Kominami Y, Yoshida S, Tanaka S, et al. Computer-aided diagnosis of colorectal polyp histology by using a real-time image recognition system and narrow-band imaging magnifying colonoscopy. Gastrointest Endosc 2016;83:643-649.

34. Rex DK, Kahi C, O'Brien M, et al. The American Society for Gastrointestinal Endoscopy PIVI (Preservation and Incorporation of Valuable Endoscopic Innovations) on realtime endoscopic assessment of the histology of diminutive colorectal polyps. Gastrointest Endosc 2011;73:419-422.

35. Byrne MF, Chapados N, Soudan F, et al. Real-time differentiation of adenomatous and hyperplastic diminutive colorectal polyps during analysis of unaltered videos of standard colonoscopy using a deep learning model. Gut 2019;68:94100.

36. Chen PJ, Lin MC, Lai MJ, Lin JC, Lu HH, Tseng VS. Accurate classification of diminutive colorectal polyps using computer-aided analysis. Gastroenterology 2018;154:568575.

37. Kudo S, Rubio CA, Teixeira CR, Kashida H, Kogure E. Pit pattern in colorectal neoplasia: endoscopic magnifying view. Endoscopy 2001;33:367-373.

38. Kudo SE, Mori Y, Wakamura K, et al. Endocytoscopy can provide additional diagnostic ability to magnifying chromoendoscopy for colorectal neoplasms. J Gastroenterol Hepatol 2014;29:83-90.
39. Takemura Y, Yoshida S, Tanaka S, et al. Quantitative analysis and development of a computer-aided system for identification of regular pit patterns of colorectal lesions. Gastrointest Endosc 2010;72:1047-1051.

40. Kiesslich R, Burg J, Vieth M, et al. Confocal laser endoscopy for diagnosing intraepithelial neoplasias and colorectal cancer in vivo. Gastroenterology 2004;127:706-713.

41. Mori Y, Kudo S, Ikehara N, et al. Comprehensive diagnostic ability of endocytoscopy compared with biopsy for colorectal neoplasms: a prospective randomized noninferiority trial. Endoscopy 2013;45:98-105.

42. Mori Y, Kudo SE, Wakamura K, et al. Novel computer-aided diagnostic system for colorectal lesions by using endocytoscopy (with videos). Gastrointest Endosc 2015;81:621-629.

43. Takeda K, Kudo SE, Mori Y, et al. Accuracy of diagnosing invasive colorectal cancer using computer-aided endocytoscopy. Endoscopy 2017;49:798-802.

44. Mori Y, Kudo SE, Misawa M, et al. Real-time use of artificial intelligence in identification of diminutive polyps during colonoscopy: a prospective study. Ann Intern Med 2018;169: 357-366.

45. Mori Y, Kudo SE, East JE, et al. Cost savings in colonoscopy with artificial intelligence-aided polyp diagnosis: an add-on analysis of a clinical trial (with video). Gastrointest Endosc 2020;92:905-911.e1.

46. Misawa M, Kudo SE, Mori Y, et al. Characterization of colorectal lesions using a computer-aided diagnostic system for narrow-band imaging endocytoscopy. Gastroenterology 2016;150:1531-1532.

47. André B, Vercauteren T, Buchner AM, Krishna M, Ayache N, Wallace MB. Software for automated classification of probebased confocal laser endomicroscopy videos of colorectal polyps. World J Gastroenterol 2012;18:5560-5569.

48. Ştefănescu D, Streba C, Cârțână ET, Săftoiu A, Gruionu G, Gruionu LG. Computer aided diagnosis for confocal laser endomicroscopy in advanced colorectal adenocarcinoma. PLoS One 2016;11:e0154863.

49. Tafreshi MK, Linard N, André B, Ayache N, Vercauteren T. Semi-automated query construction for content-based endomicroscopy video retrieval. Med Image Comput Comput Assist Interv 2014;17(Pt 1):89-96.

50. Prieto SP, Lai KK, Laryea JA, Mizell JS, Muldoon TJ. Quantitative analysis of ex vivo colorectal epithelium using an automated feature extraction algorithm for microendoscopy image data. J Med Imaging (Bellingham) 2016;3:024502.

51. Kuiper T, Alderlieste YA, Tytgat KM, et al. Automatic optical diagnosis of small colorectal lesions by laser-induced autofluorescence. Endoscopy 2015;47:56-62.

52. Rath T, Tontini GE, Vieth M, Nägel A, Neurath MF, Neumann $\mathrm{H}$. In vivo real-time assessment of colorectal polyp histology using an optical biopsy forceps system based on la- 
ser-induced fluorescence spectroscopy. Endoscopy 2016;48: 557-562.

53. Renkoski TE, Banerjee B, Graves LR, et al. Ratio images and ultraviolet $\mathrm{C}$ excitation in autofluorescence imaging of neoplasms of the human colon. J Biomed Opt 2013;18:16005.

54. Arita K, Mitsuyama K, Kawano H, et al. Quantitative analysis of colorectal mucosal lesions by autofluorescence endoscopy: discrimination of carcinomas from other lesions. Oncol Rep 2011;26:43-48.

55. Aihara H, Saito S, Inomata H, et al. Computer-aided diagnosis of neoplastic colorectal lesions using 'real-time' numerical color analysis during autofluorescence endoscopy. Eur J Gastroenterol Hepatol 2013;25:488-494.

56. Inomata $\mathrm{H}$, Tamai $\mathrm{N}$, Aihara $\mathrm{H}$, et al. Efficacy of a novel auto-fluorescence imaging system with computer-assisted color analysis for assessment of colorectal lesions. World J Gastroenterol 2013;19:7146-7153.

57. Takemura Y, Yoshida S, Tanaka S, et al. Computer-aided system for predicting the histology of colorectal tumors by using narrow-band imaging magnifying colonoscopy (with video). Gastrointest Endosc 2012;75:179-185.

58. Mori Y, Kudo SE, Misawa M, Mori K. Simultaneous detection and characterization of diminutive polyps with the use of artificial intelligence during colonoscopy. VideoGIE 2019; 4:7-10.

59. Ozawa T, Ishihara S, Fujishiro M, Kumagai Y, Shichijo S, Tada T. Automated endoscopic detection and classification of colorectal polyps using convolutional neural networks. Therap Adv Gastroenterol 2020;13:1756284820910659.

60. Ichimasa K, Kudo SE, Mori Y, et al. Artificial intelligence may help in predicting the need for additional surgery after endoscopic resection of T1 colorectal cancer. Endoscopy 2018;50:230-240.

61. Kudo SE, Takemura O, Ohtsuka K. Flat and depressed types of early colorectal cancers: from East to West. Gastrointest Endosc Clin N Am 2008;18:581-593.

62. Chinzei K, Shimizu K, Mori K, et al. Regulatory science on AI-based medical devices and systems. Adv Biomed Eng 2018;7:118-123. 